\title{
Characterization of the Microstructure of Bimodal HDPE Resin
}

\author{
By Yandi FAN, Yanhu XUE, Wei NIE, Xiangling JI, ${ }^{*}$ and Shuqin Bo*
}

In this work, two industrial bimodal high density polyethylene resins, resin A and resin $\mathrm{B}$, having similar molecular weight $\left(M_{\mathrm{w}}\right)$, molecular weight distribution $\left(M_{\mathrm{wD}}\right)$, and short-chain branching (SCB) content but different mechanical properties, were fractionated through cross-fractionation. The fractions were further characterized by GPC, ${ }^{13} \mathrm{C}$ NMR, DSC and FT-IR techniques. These two resins were firstly fractionated into two fractions, i.e., high-temperature and low-temperature fractions, via preparative solution crystallization fractionation. Resin A with much better mechanical properties contains more hightemperature fractions with longer crystallizable sequences. The SCB content in the low-temperature fraction of resin A is lower than that of resin B. Both low-temperature fractions were then further fractionated using solvent gradient fractionation (SGF). The characterization of SGF fractions indicates that most of the branches fall into the high molecular weight chains in both low-temperature fractions. However, the high molecular weight chains in the low-temperature fraction of resin A contain less SCB than that of resin B.

KEY WORDS: Polyethylene (PE) / Fractionation of Polymers / Microstructure /

Bimodal high density polyethylene (HDPE) resins benefit from their bimodality by having the strength and stiffness of HDPE, whilst retaining the high-stress-crack resistance and processability of a unimodal medium density polyethylene. ${ }^{1}$ Such bimodal HDPE resins are ideally suited to the application demands of pipes for gas and water distribution.

Bimodal HDPE resins are produced by tandem processes that use reactor combinations of loop, slurry, and gas-phase by themselves or in combination with one another. In the first reactor, high amounts of hydrogen are fed with ethylene. This process leads to the formation of low-molar-mass polyethylene. The second reactor is loaded with much less hydrogen to form a high- or very high-molar-mass polyethylene. ${ }^{2}$ This process allows for further essential product modification, specifically the incorporation of comonomer in the long polymer chains within the second reactor. There is also a reversed mode wherein the high-molar-mass component is produced firstly, followed by a low-molar-mass component. These products build up a polymer alloy in solid state with crystalline and amorphous regions in between. The crystalline regions are mainly formed by low-molar-mass homo-polyethylene. The high-molar-mass copolymers form the amorphous regions and act as tie molecules that connect the crystal lamellae (Figure 29 in ref 2). These tie molecules that possess short-chain branching (SCB) effectively hinder the pullout of the polymer chains from the crystallites. In this manner, the strength and resistance to slow crack growth of the resin are greatly improved finally.

Recently, there has been an emphasis in developing relations between microstructure and end-use physical/mechanical properties of bimodal HDPE resins. Many investigators have pointed out that the amount and distribution of SCB are significant factors in determining the physical properties of bimodal HDPE resins. ${ }^{3-9}$ Hubert and coworkers ${ }^{3}$ considered that more complicated molecular architectures make crystal- lization of regular chain folding difficult, and that inter- and intra-molecular heterogeneity of the comonomer distribution are efficient means of generating tie molecules and random chain folding at the expense of regular chain folding. As a result, bimodal HDPE resins have a higher degree of comonomer incorporation for a given crystallinity compared with unimodal HDPE resins. This causes a considerable increase in the degree of entanglement of polymer chains, thus improving the mechanical properties available. Hence, the comonomer distribution turns out to be an additional parameter of the molecular architecture available for mechanical properties, besides comonomer concentration and nature, as well as molecular weight distribution $\left(M_{\mathrm{wD}}\right)$. Detailed polymer analysis can only be accomplished through the use of fractionation to separate molecular species according to their different structures.

Many analytical techniques have been employed to measure the structural heterogeneity of polyolefins. Temperature rising elution fractionation (TREF), a technique that fractionates semicrystalline polymers according to their solubility-temperature relationship, has been widely used in the characterization of compositional heterogeneity of polyolefins. ${ }^{10-12}$ Separation occurs typically by comonomer content, degree of tacticity and number of branch sequence lengths. Solvent gradient fractionation (SGF) is suitable for fractionating polyolefins by molecular weight differences. ${ }^{13-15}$ As reported in the literature,${ }^{14}$ the metallocene polyethylene copolymers were initially fractionated by SGF, and then a representative SGF fraction was further sorted out using TREF. Using this cross-fractionation $(\mathrm{CF})$ technique, Hsieh et al. proved intermolecular compositional heterogeneity for a metallocene short-chainbranched polyethylene copolymer.

In this paper, two bimodal HDPE resins with similar 1butene content and average molecular weight and molecular

State Key Laboratory of Polymer Physics and Chemistry, Changchun Institute of Applied Chemistry, Chinese Academy of Sciences, Changchun 130022, People's Republic of China

*To whom correspondence should be addressed (Tel: +86-431-8526-2876, Fax: +86-431-8568-5653, E-mail: xlji@ ciac.jl.cn, sqbo@ @iac.jl.cn). 
weight distribution, but different mechanical properties were firstly fractionated by preparative solution crystallization fractionation which fractionates semicrystalline polymers during the cooling process according to their solubility-temperature relationship, and the chosen fractions were then fractionated by SGF. These two resins and their fractions were investigated by high temperature gel permeation chromatography (GPC), carbon-13 nuclear magnetic resonance ( ${ }^{13} \mathrm{C}$ NMR), differential scanning calorimetry (DSC) and fourier transform infrared (FT-IR) techniques. From these analytical results, it is possible to understand the microstructure of these two HDPE resins more intensively.

\section{EXPERIMENTAL}

\section{Materials}

Two industrial bimodal HDPE resins used in this study were kindly provided by the China Petrochemical Corporation and coded as resin $\mathrm{A}$ and resin $\mathrm{B}$, respectively. The density of resin $A$ and $B$ are 0.9493 and $0.9483 \mathrm{~g} / \mathrm{cm}^{3}$, respectively. These two resins are ethylene/1-butene copolymers and resin A exhibits much better mechanical properties. Resin A qualified for the Minimum Required Strength (MRS) 10 rating. ${ }^{1}$ To qualify for the MRS 10 rating, the pipe must withstand a minimum circumference (hoop) stress of $10 \mathrm{MPa}$ for up to 50 years at $20^{\circ} \mathrm{C}$ according to the ISO test method. ${ }^{16}$ But minimum circumference stress of resin $\mathrm{B}$ is lower than $10 \mathrm{MPa}$, and it can not qualify for MRS 10 rating.

\section{Preparative Solution Crystallization Fractionation}

About $6 \mathrm{~g}$ of polymer was dissolved in $600 \mathrm{~mL}$ of xylene at $135^{\circ} \mathrm{C}$, while $1 \times 10^{-3} \mathrm{~g} / \mathrm{mL}$ 2,6-di-tert-butyl-4-methylphenol (BHT) was added to xylene as an antioxidant. The solution was subsequently cooled to $91{ }^{\circ} \mathrm{C}$ under continuous stirring for $4 \mathrm{~h}$, and then was kept at this temperature for $16 \mathrm{~h}$ under stirring, and was finally separated into two phases: the concentrated phase and the dilute phase. The concentrated phase was filtered at $91{ }^{\circ} \mathrm{C}$, and the precipitate from this phase extracted by removing the residual solvent was called fraction 1 (hightemperature fraction). The dilute phase was cooled down to room temperature naturally and two fractions were obtained; the fraction insoluble in xylene called fraction 2 (low-temperature fraction) and the fraction dissolved in xylene named fraction 3. The obtained polymer fractions were dried in a vacuum oven at $50{ }^{\circ} \mathrm{C}$ until they reached a constant weight.

\section{Solvent Gradient Fractionation}

The SGF technique is most suitable for fractionating polyolefins by molecular weight differences. The low-temperature fractions (fraction 2) of these two resins were further fractionated by SGF. 1,2,4-trimethylbenzene (TMB) and methyl cellosolve (MCS) were used as good and poor solvents, respectively. The total weight of fraction 2 for fractionation was about $2 \mathrm{~g}$. More details on the experiment of SGF can be found in ref 14 .

\section{Characterization of Resins and Fractions}

The molecular weight and molecular weight distribution of HDPE resins and their fractions were determined by PL-GPC 220 high temperature gel permeation chromatography (Polymer Laboratories Ltd.) at $150{ }^{\circ} \mathrm{C}$. The columns used were three PLgel $10 \mu \mathrm{m}$ mixed-B LS columns $(300 \mathrm{~mm} \times 7.5 \mathrm{~mm})$. The eluent was 1,2,4-trichlorobenzene stabilized with $5 \times 10^{-4} \mathrm{~g}$ / $\mathrm{mL}$ BHT and was filtered with a $0.2 \mu \mathrm{m}$ pore size membrane before use. The injection volume was $200 \mu \mathrm{L}$ and the flow rate was $1.0 \mathrm{~mL} / \mathrm{min}$. Calibration was made by polystyrene standard EasiCal PS-1 (PL Ltd.).

${ }^{13} \mathrm{C}$ NMR spectra were recorded at $140{ }^{\circ} \mathrm{C}$ on a Varian Unity $400 \mathrm{MHz}$ NMR spectrometer. Polymer solutions were prepared with $70-75 \mathrm{mg}$ of polymer in $0.5 \mathrm{~mL}$ of deuterated $o$-dichlorobenzene at $125^{\circ} \mathrm{C}$.

FT-IR analyses were performed using a Bruker IFS 66v/S spectrometer with a resolution of $4 \mathrm{~cm}^{-1}$. Transmission spectra were recorded with a DTGS detector with 32 scans co-added. Samples were prepared for FT-IR spectroscopy by hot pressing approximately $100 \mathrm{mg}$ of polymer between polyester sheets in a mold at temperatures ranging from $110-160^{\circ} \mathrm{C}$, depending on the melting point of the samples.

The thermal behavior of samples was measured on a TA Instrument TMDSC Q100. An indium standard was used to calibrate the instrument. The samples (about $6 \mathrm{mg}$ ) were firstly heated to $160^{\circ} \mathrm{C}$ at a rate of $10^{\circ} \mathrm{C} / \mathrm{min}$, held at $160^{\circ} \mathrm{C}$ for $5 \mathrm{~min}$ to erase thermal history, then cooled to $20^{\circ} \mathrm{C}$ at $10^{\circ} \mathrm{C} /$ min, held at $20^{\circ} \mathrm{C}$ for $1 \mathrm{~min}$, and finally heated again to $160^{\circ} \mathrm{C}$ at $10^{\circ} \mathrm{C} / \mathrm{min}$. The $2 \mathrm{nd}$ melting curves are recorded and given in the results.

\section{RESULTS AND DISCUSSION}

\section{Characterization of the Whole Samples}

The GPC curves of resins A and B are shown in Figure 1. Both resins exhibit similar bimodal $M_{\mathrm{wD}}$. Table I lists the results for the GPC and ${ }^{13} \mathrm{C}$ NMR analysis of the two resins. GPC is an entropically controlled separation technique in which molecules are separated on the basis of hydrodynamic

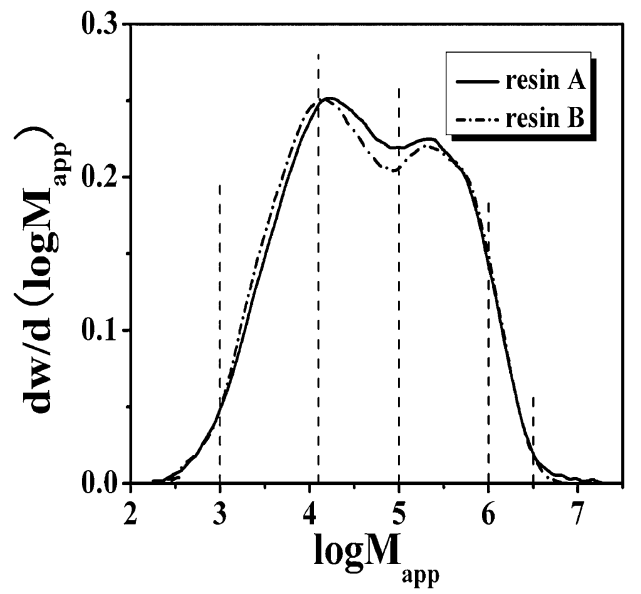

Figure 1. Molecular weight distribution profiles of resins $A$ and $B$. 
Table I. Molecular characteristics of HDPE resins

\begin{tabular}{ccccc}
\hline HDPE resin & $\begin{array}{c}M_{\mathrm{w}} \\
\left(10^{3}\right)\end{array}$ & $\begin{array}{c}M_{\mathrm{n}} \\
\left(10^{3}\right)\end{array}$ & $M_{\mathrm{w}} / M_{\mathrm{n}}$ & $\begin{array}{c}\text { SCB content } \\
(\mathrm{mol} \%)\end{array}$ \\
\hline Resin A & 261 & 8.69 & 30.1 & 0.55 \\
Resin B & 237 & 8.39 & 28.3 & 0.65 \\
\hline
\end{tabular}

Table II. Weight percent of different $M_{\mathrm{wR}}$ of resins A and B

\begin{tabular}{ccc}
\hline$M_{\mathrm{wR}}$ & \multicolumn{2}{c}{ HDPE resin } \\
\cline { 2 - 3 }$\left(10^{4}\right)$ & Resin A (wt \%) & Resin B (wt \%) \\
\hline$<0.1$ & 1.8 & 1.8 \\
$0.1-1.3$ & 26.3 & 28.2 \\
$1.3-10$ & 33.1 & 31.8 \\
$10-100$ & 32.2 & 31.9 \\
$100-320$ & 5.9 & 6.0 \\
$>320$ & 0.7 & 0.3 \\
$>1000$ & 0.066 & 0 \\
\hline
\end{tabular}

volume. In this work, the molecular weight data of samples are calculated by use of the PS calibration, so all molecular weight data from GPC measurement are apparent molecular weight. In addition, both ethylene/1-butene copolymers have very short branching chain and very low SCB content (less than $1 \mathrm{~mol} \%$ ), thus the influence of SCB on the hydrodynamic volume of copolymer molecule is very slight.

Resin A has a higher molecular weight $\left(M_{\mathrm{w}}=261000 \mathrm{~g} /\right.$ mol) and a broader $M_{\mathrm{wD}}(30.1)$ than resin B $\left(M_{\mathrm{w}}=237000 \mathrm{~g} /\right.$ mol, $\left.M_{\mathrm{wD}}=28.3\right)$. In general, the low $M_{\mathrm{w}}$ chains facilitate processability by an inherent lubrication effect while the high $M_{\mathrm{w}}$ chains provide good mechanical properties. The above $M_{\mathrm{wD}}$ profiles were divided into several molecular weight regions $\left(M_{\mathrm{wR}}\right)$ as indicated in Figure 1. The weight percent of each region is calculated by cumulative $M_{\mathrm{wD}}$ curves and the details are listed in Table II. Compared with resin B, resin A has a lower amount of $M_{\mathrm{w}}<1.3 \times 10^{4}$ fraction but a relative larger amount of $M_{\mathrm{w}}>3.2 \times 10^{6}$ fraction.

The ${ }^{13} \mathrm{C}$ NMR spectra of these two HDPE resins are given in Figure 2. The quantitative analysis of branching in polyethylene has become a subject of much investigation due to the commercial importance of this material. The assignments are well established at present for the products containing less than $10 \mathrm{~mol} \%$ of the comonomer. ${ }^{17-21}$ In Figure 2, the intensity of branching (br) is much lower than that of isolate $\mathrm{CH}_{2}$. This indicates that the comonomer content is very low in these two resins. Meanwhile, there is no detectable contiguous comonomer sequence in NMR spectra. This means that almost all comonomers are incorporated isolated, and the same feature has been reported in the literature. ${ }^{21}$ The calculation of comonomer composition follows the method reported by Pooter, ${ }^{17}$ and the results are listed in Table I. Resins A and B have very low comonomer content $(0.55$ and $0.65 \mathrm{~mol} \%$, respectively), but the comonomer content of resin $\mathrm{B}$ is slightly higher than that of resin A. However, the analysis on average values of microstructure is not sufficient to completely explain the different mechanical properties. Acquiring information concerning the microstructure distribution of HDPE resin is

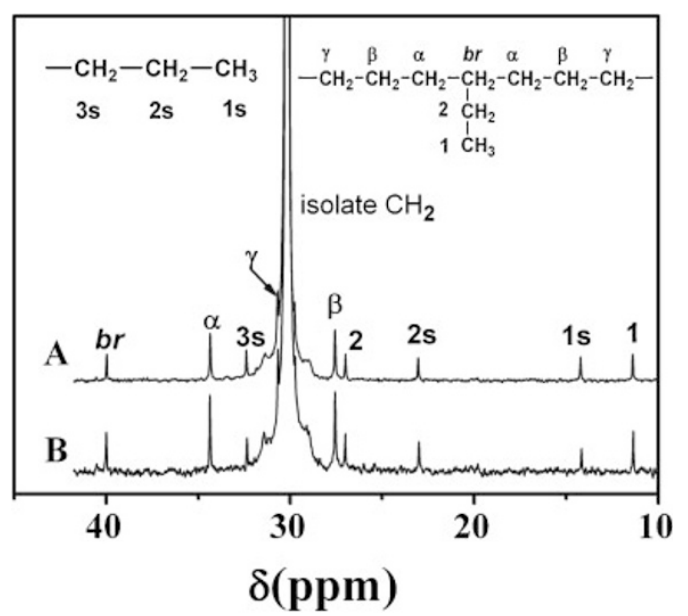

Figure 2. ${ }^{13} \mathrm{C}$ NMR spectra of resins $\mathrm{A}$ and $\mathrm{B}$.

necessary in order to elucidate the relationship between its microstructure and mechanical properties. This can be obtained via cross-fractionation and subsequent characterization of fractions by means of GPC, NMR, DSC and FT-IR.

\section{GPC and ${ }^{13} \mathrm{C}$ NMR Analysis of Fractions from Preparative Solution Crystallization Fractionation}

Thermal fractionation can give some qualitative information on segment distribution in branched ethylene copolymer chains. The stepwise isothermal crystallization (SIC) method is the separation of the bulk of high temperature melting and low temperature melting species corresponding to comonomer poor and comonomer rich chains, respectively. The ratio of these two species was suggested to be an indicator of long-term behavior because the comonomer rich part is likely to provide a high rate of tie molecules. ${ }^{22,23}$ Two melting peaks were obtained in the DSC heating curves of resin A after stepwise isothermal crystallization (ref 24). The temperature of the minimum point between those two melting peaks is $120^{\circ} \mathrm{C}$. Preparative solution crystallization fractionation was used to get these two fractions with different comonomer contents for further characterization. The solution fractionation temperature could be set according to the DSC result. The detail is as follows. As shown in Figure 29 of ref 10, the DSC peak temperatures of the TREF fractions of a LLDPE sample were plotted against the elution temperature. Based on this figure and DSC peak temperature of the TREF fractions of ethylene/ 1-butene copolymer reported in ref 25-27, the solution fractionation temperature was set at $91^{\circ} \mathrm{C}$, corresponding to about $120^{\circ} \mathrm{C}$ in the DSC heating curve.

Both resins were firstly fractionated by preparative solution crystallization fractionation and three fractions were obtained (A-1, A-2, A-3 for resin A and B-1, B-2, B-3 for resin B). Here, we neglect the A-3 and B-3 due to a small amount in these two fractions. The total recoveries of fractionation are $94.5 \%$ and $96.0 \%$ for resin A and resin B, respectively. The related information and the molecular characterization data are summarized in Table III. Figure 3(a) and 3(b) show the GPC 
Table III. The fractionation results and molecular characterization data

\begin{tabular}{crcccc}
\hline Fraction & wt $\%$ & $\begin{array}{c}M_{\mathrm{w}} \\
\left(10^{3}\right)\end{array}$ & $\begin{array}{c}M_{\mathrm{n}} \\
\left(10^{3}\right)\end{array}$ & $M_{\mathrm{w}} / M_{\mathrm{n}}$ & $\begin{array}{c}\text { SCB content } \\
(\mathrm{mol} \%)\end{array}$ \\
\hline A-1 & 30.2 & 222 & 28.6 & 7.76 & 0.28 \\
A-2 & 69.4 & 297 & 7.52 & 39.5 & 0.69 \\
A-3 & 0.4 & - & - & - & - \\
B-1 & 25.7 & 200 & 29.4 & 6.80 & 0.23 \\
B-2 & 74.0 & 260 & 7.01 & 37.1 & 0.83 \\
B-3 & 0.3 & - & - & - & - \\
\hline
\end{tabular}

profiles of the original samples along with the weighted GPC curves of the fractions and their sums. The sums of the GPC curves of the fractions are in good agreement with that of the unfractionated samples. This suggests that the preparative solution crystallization fractionation used in this work is efficient and no degradation can be found.

Figure 4(a) shows the GPC curves of A-1 and B-1, which are unimodal $M_{\mathrm{wD}}$. Interestingly, they have approximately average molecular weight. However, A-1 contains more low $M_{\mathrm{w}}$ chains, thus exhibiting a relatively low $M_{\mathrm{n}}$ and broad $M_{\mathrm{wD}}$. The ${ }^{13} \mathrm{C}$ NMR results show that the SCB content in both fraction 1s (i.e., A-1 and B-1) is $0.28 \%$ and $0.23 \%$, the weight percent of A-1 is about $18 \%$ higher than that of B-1. This indicates that resin $\mathrm{A}$ has more high-temperature fractions which have longer crystallizable sequences. The GPC curves of A-2 and B-2 in Figure 4(b) show a typical bimodal $M_{\mathrm{wD}}$. A-2 has higher $M_{\mathrm{w}}$ of 297000 than B-2 of 260000 . We noticed that the $M_{\mathrm{w}}$ of A-2 or B-2 is higher than that of A-1 or B-1 (297000, 222000 for resin A, 260000, 200000 for resin B). Furthermore, the SCB content in A-2 and B-2 are $0.69 \%$ and $0.83 \%, 2-3$ times higher than that in A-1 and B-1, respectively. This implies that preparative solution crystallization fractionation is an effective method in fractionating these two HDPE resins by intermolecular SCB content differences. Unfortunately, only a few fraction $3 \mathrm{~s}$ are available, making it difficult to carry out any further characterization.

The values of $\mathrm{W}_{2} / \mathrm{W}_{1}$ (the mass ratios of fraction 2 and fraction 1) are 2.30 and 2.88 for resin $\mathrm{A}$ and resin $\mathrm{B}$, respectively. The difference of $\mathrm{SCB}$ distribution in resins $\mathrm{A}$ and $\mathrm{B}$ induces the different $\mathrm{W}_{2} / \mathrm{W}_{1}$ and also influences the formation of tie molecules. Fraction 1 contains less SCB content than fraction 2 , the melting temperature $\left(T_{\mathrm{m}}\right)$ and the fusion enthalpy $\left(\Delta H_{\mathrm{m}}\right)$ of fraction 1 are higher than that of fraction $2\left(T_{\mathrm{m}}: 132.3,126.7^{\circ} \mathrm{C}\right.$ for A-1 and A-2, 133.0,
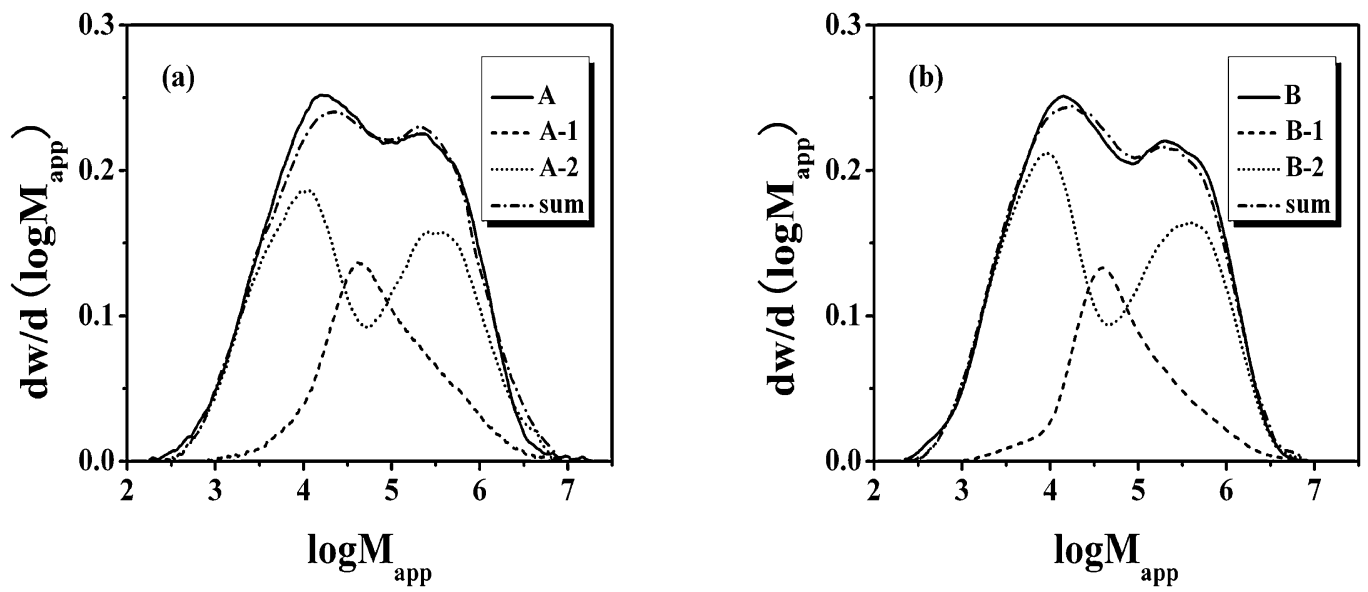

Figure 3. Molecular weight distribution profiles of resin A (a) and resin B (b) with the weighted distributions of the fractions and their sums.
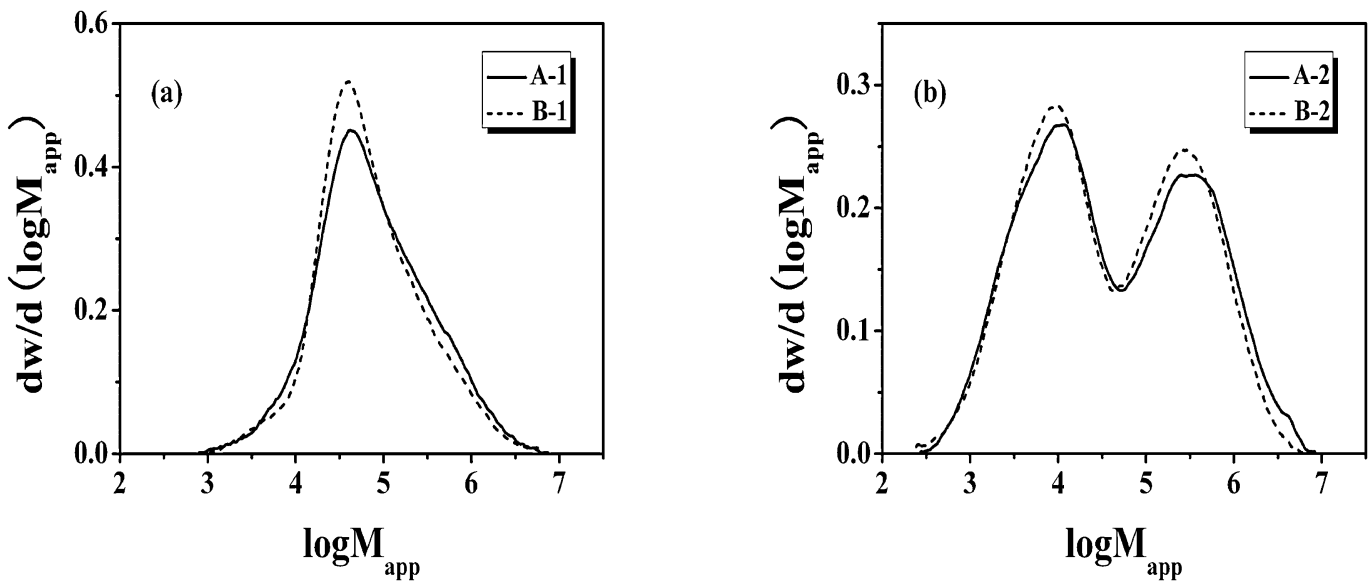

Figure 4. Molecular weight distribution profiles of the fraction $1 \mathrm{~s}(\mathrm{a})$ and fraction $2 \mathrm{~s}(\mathrm{~b})$ of resins $\mathrm{A}$ and $\mathrm{B}$. 
$127.3{ }^{\circ} \mathrm{C}$ for B-1 and B-2. $\Delta H_{\mathrm{m}}: 170.3,162.8 \mathrm{~J} / \mathrm{g}$ for $\mathrm{A}-1$ and $\mathrm{A}-2,174.6,160.9 \mathrm{~J} / \mathrm{g}$ for $\mathrm{B}-1$ and $\mathrm{B}-2)$. Because fraction 1 contains less SCB content, a few tie molecules are included in this polymer population. Meanwhile, fraction 2, the comonomer rich part, is likely to provide more tie molecules. Resin B contains more fraction 2 but exhibits worse properties, so fraction 2 was further fractionated using SGF to investigate SCB distribution across $M_{\mathrm{wD}}$.

\section{SCB Distribution within Low-temperature Fractions}

Choosing the appropriate good-poor solvent pair is very important for solvent gradient fractionation. There are few results of SGF on bimodal HDPE resin that have been reported in the literature. Hsieh et al. ${ }^{14}$ investigated the intermolecular compositional heterogeneity of a metallocene-catalyzed PE copolymers using SGF in combination with temperature gradient fractionation (TGF). In their work, 1,2,4-tricholorobenzene (TCB) and $n$-butyl cellosolve (BCS) were used as good and poor solvents, respectively. They found that BCS is a better solvent for more branched polyolefin molecules because higher $M_{\mathrm{w}}$ molecules with higher SCB content are expected to be found in the same SGF fraction as the lower $M_{\mathrm{w}}$ molecules with less SCB content. For the bimodal HDPE resin, SCB is mainly found in the high $M_{\mathrm{w}}$ tail of the $M_{\mathrm{wD}}$. We found that unimodal SGF fractions are difficult to obtain using the TCBBCS solvent system. In this paper, MCS and TMB were used as poor and good solvents, respectively. However, MCS might be a poorer solvent for branched polyolefin molecules than BCS. Fraction 2 can be soluble in the 50/50 TCB/BCS mixture but only be totally dissolved in the TMB/MCS mixture with MCS lower than $20 \mathrm{vol} \%$ at $130^{\circ} \mathrm{C}$. The TMB/MCS mixture is more suitable for SGF of fraction 2 with bimodal $M_{\mathrm{wD}}$. Unfortunately, the column and elution system we used are too simple and they influence the fractionation result, so not all SGF fractions we obtained are unimodal shape.

The total recoveries of SGF are $94.6 \%$ and $99.8 \%$ for A-2 and B-2, respectively. The results are summarized in Tables IV and V. As shown in Figures 5 and 6, the SGF fractions of both A-2 and B-2 are almost bimodal $M_{\mathrm{wD}}$ and broad in $M_{\mathrm{wD}}$. For A-2 and B-2, the fractions collected from the elution solvent with TMB less than 70 vol \% have a high molecular weight tail, while those fractions collected from the elution solvent with TMB more than 70 vol \% have a relatively low molecular weight tail. Fraction 1 of A-2 has a rather broader $M_{\mathrm{wD}}$ of 95.3 and higher $M_{\mathrm{w}}$ of 88000 . It possibly contains molecular chains with high SCB content and higher $M_{\mathrm{w}}$, which remain in the solution at the end of the slow-cooling process. Due to the existence of high or low molecular weight tails in the GPC curves, these SGF fractions have relatively broad $M_{\mathrm{wD}}$ and not all the $M_{\mathrm{w}}$ of fractions increase with TMB volume percent in the mixed solvent. Nonetheless, the molecular weights of the main peak of the fractions indeed increase with TMB volume percent. For the last two or three fractions of A-2 and B-2, the molecular weights are more than 200,000, and these fractions accounted for nearly $30 \mathrm{wt} \%$ of A-2 and B-2. We infer that the sample degradated in the latter period of fractionation.
Table IV. Solvent Gradient Fractionation of A-2 and Molecular Characterization Data

\begin{tabular}{cccrccccc}
\hline Fraction $\begin{array}{c}\text { Temp. } \\
\left({ }^{\circ} \mathrm{C}\right)\end{array}$ & MCS/TMB wt \% Cum.wt \% & $\begin{array}{c}M_{\mathrm{w}} \\
\left(10^{3}\right)\end{array}$ & $\begin{array}{c}M_{\mathrm{n}} \\
\left(10^{3}\right)\end{array}$ & $M_{\mathrm{w}} / M_{\mathrm{n}}$ & $\begin{array}{c}\text { SCB content } \\
(\mathrm{mol} \%)\end{array}$ \\
\hline $1^{\mathrm{a}}$ & 100 & $100 / 0$ & 1.0 & 1.0 & 88.1 & 0.924 & 95.3 & - \\
2 & 110 & $50 / 50$ & 10.6 & 11.6 & 9.91 & 1.80 & 5.51 & - \\
3 & 110 & $45 / 55$ & 6.1 & 17.7 & 27.6 & 4.11 & 6.72 & - \\
4 & 110 & $40 / 60$ & 7.0 & 24.7 & 36.7 & 5.98 & 6.14 & - \\
5 & 110 & $35 / 65$ & 14.1 & 38.8 & 28.3 & 8.85 & 3.20 & 0.35 \\
6 & 110 & $32 / 68$ & 8.2 & 47.0 & 43.6 & 13.8 & 3.16 & 0.55 \\
7 & 110 & $30 / 70$ & 6.9 & 53.9 & 73.2 & 21.4 & 3.42 & 0.77 \\
8 & 110 & $27 / 73$ & 16.7 & 70.6 & 258 & 40.5 & 6.37 & 1.07 \\
9 & 110 & $25 / 75$ & 18.6 & 89.2 & 433 & 95.4 & 4.54 & 0.91 \\
10 & 140 & $0 / 100$ & 10.8 & 100 & 495 & 133 & 3.72 & 1.00 \\
\hline
\end{tabular}

a Fraction 1 is a mixed part with both fraction soluble in the $100 \%$ MCS at $100^{\circ} \mathrm{C}$ and room temperature fraction after the slow-cooling process.

Table V. Solvent Gradient Fractionation of B-2 and Molecular Characterization Data

\begin{tabular}{ccccccccc}
\hline Fraction $\begin{array}{c}\text { Temp. } \\
\left({ }^{\circ} \mathrm{C}\right)\end{array}$ & MCS/TMB & wt \% & Cum.wt \% & $\begin{array}{c}M_{\mathrm{w}} \\
\left(10^{3}\right)\end{array}$ & $\begin{array}{c}M_{\mathrm{n}} \\
\left(10^{3}\right)\end{array}$ & $M_{\mathrm{w}} / M_{\mathrm{n}}$ & $\begin{array}{c}\text { SCB content } \\
(\mathrm{mol} \%)\end{array}$ \\
\hline $1^{\mathrm{a}}$ & 100 & $100 / 0$ & 2.9 & 2.9 & 1.28 & 1.06 & 1.21 & - \\
2 & 110 & $50 / 50$ & 5.0 & 7.9 & 2.64 & 2.05 & 1.29 & - \\
3 & 110 & $45 / 55$ & 5.4 & 13.3 & 3.84 & 2.81 & 1.37 & - \\
4 & 110 & $41 / 59$ & 6.2 & 19.5 & 41.0 & 4.86 & 8.44 & - \\
5 & 110 & $37 / 63$ & 9.3 & 28.8 & 41.2 & 7.06 & 5.84 & - \\
6 & 110 & $34 / 66$ & 9.7 & 38.5 & 59.3 & 10.5 & 5.65 & 0.43 \\
7 & 110 & $32 / 68$ & 8.0 & 46.5 & 56.3 & 14.7 & 3.83 & 0.49 \\
8 & 110 & $30 / 70$ & 9.9 & 56.4 & 106 & 26.7 & 3.97 & 1.02 \\
9 & 110 & $28 / 72$ & 12.3 & 68.7 & 194 & 51.9 & 3.74 & 1.30 \\
10 & 110 & $26 / 74$ & 14.6 & 83.3 & 386 & 59.2 & 6.52 & 1.13 \\
11 & 110 & $24 / 76$ & 10.7 & 94.0 & 479 & 76.3 & 6.28 & 0.98 \\
12 & 140 & $0 / 100$ & 6.0 & 100 & 550 & 62.2 & 8.84 & 1.02 \\
\hline
\end{tabular}

a Fraction 1 is a mixed part with both fraction soluble in the $100 \%$ MCS at $100^{\circ} \mathrm{C}$ and room temperature fraction after the slow-cooling process.

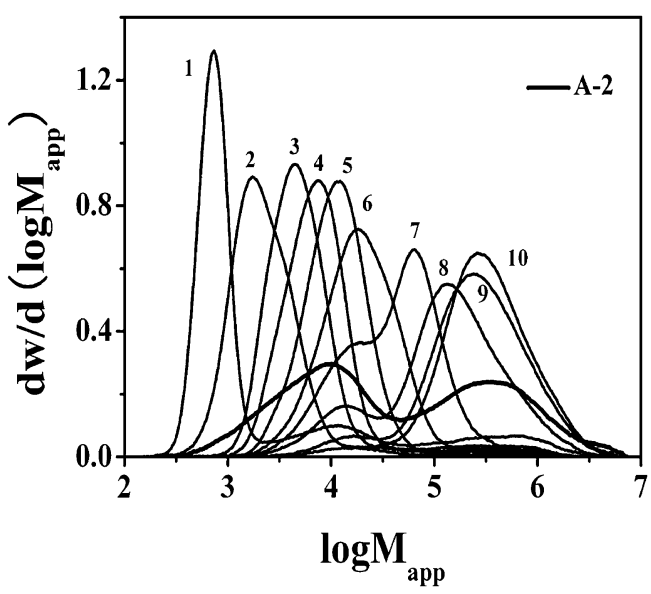

Figure 5. Molecular weight distribution profiles of A-2 and its fractions.

The SCB distributions of A-2 and B-2 are plotted as a function of $M_{\mathrm{w}}$ in Figure 7. The SCB content of the fractions are obtained from FT-IR spectra ${ }^{28}$ according to the calibration of a series of bimodal HDPE resins previously analyzed by 


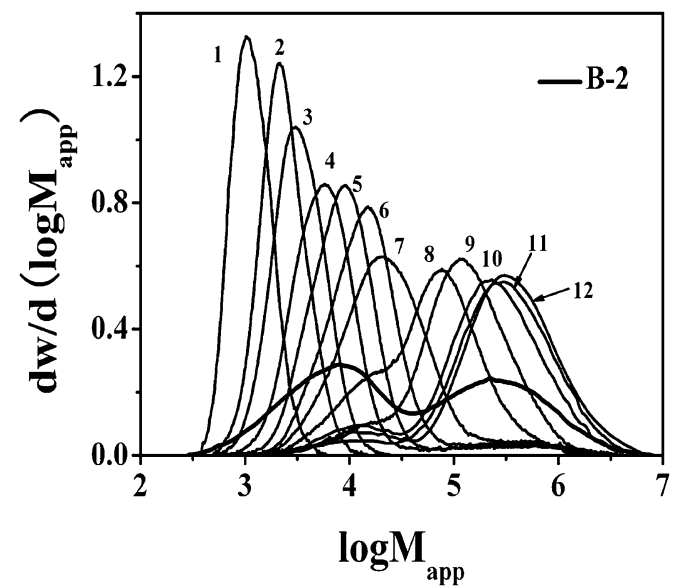

Figure 6. Molecular weight distribution profiles of B-2 and its fractions.

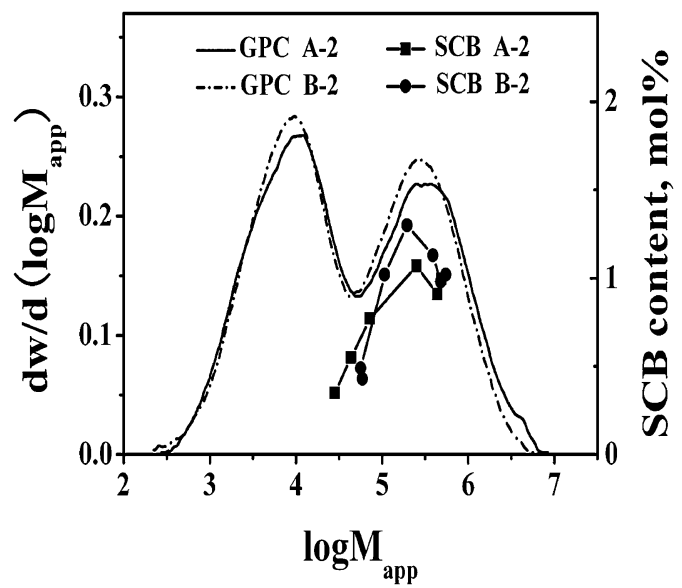

Figure 7. Short-chain branching distribution profiles of the SGF fractions superimposed on the $M_{\mathrm{wD}} \mathrm{S}$ of $\mathrm{A}-2$ and $\mathrm{B}-2$.

${ }^{13} \mathrm{C}$ NMR technique. The mass of low $M_{\mathrm{w}}$ fractions is too low to be analyzed by either FT-IR or ${ }^{13} \mathrm{C}$ NMR. Although SCB content was not measured for all the fractions, more data points have been obtained across the whole $M_{\mathrm{wD}}$. As shown in Figure 7, although A-2 and B-2 degradated in the latter period of SGF, we could find that most of the branching fall into the high molecular weight side and the SCB content reaches a maximum at $\sim 258000$ for A-2 and $\sim 194000$ for B-2. The molecular chains with $M_{\mathrm{w}}$ less than 81000 in A-2 contain more SCB than that in B-2, but the molecular chains with $M_{\mathrm{w}}$ higher than 81000 in A-2 contain less SCB than that in B-2. Most of SCB in A-2 and B-2 falls into the molecular chains with $M_{\mathrm{w}}$ higher than 81000 . The SCB content of A-2 is less than that of B-2, and molecular chains with $M_{\mathrm{w}}$ higher than 81000 in A-2 contain less SCB than that in B-2. The short-chain branching distribution in the bimodal HDPE resin should be a key factor to finally control different mechanical properties. Resin A exhibits a relatively homogeneous SCB distribution and provides tie molecules effectively, which facilitates to improve mechanical properties finally.

\section{CONCLUSIONS}

Cross-fractionation, i.e., solution crystallization fractionation and solvent gradient fractionation, was applied to two industrial bimodal HDPE resins (resin A and resin B), which have similar molecular weight data and low SCB content of $\sim 0.6 \mathrm{~mol} \%$ but different mechanical properties, and resin $\mathrm{A}$ exhibits much better mechanical properties than resin B. The characterization of microstructure reveals that the weight percent of high-temperature fraction with longer crystallizable sequence in resin $\mathrm{A}$ is higher than that in resin B, and most of the branching in both resins falls into the high $M_{\mathrm{w}}$ chains. However, the molecular chains with $M_{\mathrm{w}}$ higher than 81000 in low-temperature fraction of resin A contain less SCB than that of resin $\mathrm{B}$. It means that resin A exhibits a relatively homogeneous SCB distribution. The short-chain branching distribution in the bimodal HDPE resin should be a key factor to finally influence mechanical properties. The microstructure of resin A facilitate to exhibit better mechanical properties in application.

Acknowledgment. This work was subsidized by the National Basic Research Program of China (2005CB623806) and National Natural Science Foundation of China (20734006, 50621302). The authors would also like to thank Mr. Xingjie Zhan and Dr. Zhaohui Su for their assistance in the FT-IR experiments.

Received: February 8, 2009

Accepted: April 21, 2009

Published: June 17, 2009

\section{REFERENCES}

1. L. L. Böhm, Trends Polym. Sci., 4, 408 (1996).

2. L. L. Böhm, Angew. Chem., Int. Ed., 42, 5010 (2003).

3. L. Hubert, L. David, R. Séguéla, G. Vigier, C. Degoulet, and Y. Germain, Polymer, 42, 8425 (2001).

4. R. K. Krishnaswamy, Q. Yang, L. Fernandez-Ballester, and J. A. Kornfield, Macromolecules, 41, 1693 (2008).

5. L. L. Böhm, H. F. Enderle, and M. Fleissner, Adv. Mater., 4, 234 (1992).

6. J. Cazenave, R. Séguéla, B. Sixou, and Y. Germain, Polymer, 47, 3904 (2006).

7. P. J. DesLauriers, M. P. Mcdaniel, D. C. Rohlfing, R. K. Krishnaswamy, S. J. Secora, E. A. Benham, P. L. Maeger, A. R. Wolfe, A. M. Sukhadia, and B. B. Beaulieu, Polym. Eng. Sci., 45, 1203 (2005).

8. P. J. DesLauriers, D. C. Rohlfing, and E. T. Hsieh, Polymer, 43, 159 (2002).

9. A. Krumme, A. Lehtinen, and A. Viikna, Eur. Polym. J., 40, 359 (2004).

10. J. B. P. Soares and A. E. Hamielec, Polymer, 36, 1639 (1995).

11. J. Xu and L. Feng, Eur. Polym. J., 36, 867 (2000).

12. Y. Feng and J. N. Hay, Polymer, 39, 6589 (1998).

13. S. Hosoda, Polym. J., 20, 383 (1988).

14. E. T. Hsieh, J. Macromol. Sci. Phys., B36, 615 (1997).

15. P. Schouterden, G. Groeninckx, B. Van der Heijden, and F. Jansen, Polymer, 28, 2099 (1987).

16. ISO (1994) Thermoplastic pipes for the transport of fluids-Methods of extrapolation of hydrostatic stress rupture data to determine the 
long-term hydrostatic strength of thermoplastic pipe materials: ISO/ TR 9080, International Organization for Standardization, Geneva, Switzerland.

17. M. De Pooter, P. B. Smith, K. K. Dohrer, K. F. Bennett, M. D. Meadows, C. G. Smith, H. P. Schouwenaars, and R. A. Geerards, J. Appl. Polym. Sci., 42, 399 (1991).

18. E. T. Hsieh and J. C. Randall, Macromolecules, 15, 1402 (1982).

19. J. C. Randall, J. Macromol. Sci. Rev. Macromol. Chem. Phys., C29, 201 (1989)

20. T. Usami and S. Takayama, Macromolecules, 17, 1756 (1984).

21. Y. M. Kim, C. H. Kim, and J. K. Park, J. Appl. Polym. Sci., 60, 2469 (1996).

22. F. L. Scholten and H. J. M. Rijpkema, presented at Proceedings of
Plastics Pipes VIII Conference of the Plastics and Rubber Institute, Kongingshof, the Netherlands, September 1992.

23. D. Gueugnaut, presented at Proceeding of Plastics Piping Systems for Gas Distribution International Symposium of the Gas Research Institute, Lake Buena Vista, FL, October 1997.

24. T. He, The Report of the National Basic Research Program of China, 2005CB623806, 2007.

25. L. Wild, T. Ryle, and D. Knobeloch, Polym. Prepr. (Am. Chem. Soc., Div. Polym. Chem.), 23, 133 (1986).

26. M. Zhang, D. T. Lynch, and S. E. Wanke, Polymer, 42, 3067 (2001).

27. T. Usami, Y. Gotoh, and S. Takayama, Macromolecules, 19, 2722 (1986).

28. J. P. Blitz and D. C. McFaddin, J. Appl. Polym. Sci., 51, 13 (1994). 